\title{
The Effect of Salt Stoichiometry on Protein-Salt Interactions Determined by Ternary Diffusion in Aqueous Solutions
}

\author{
Onofrio Annunziata, ${ }^{*}, \dagger$ Luigi Paduano, ${ }^{\dagger, \downarrow}$ and John G. Albright ${ }^{\dagger}$ \\ Department of Chemistry, Texas Christian University, Fort Worth, Texas 76129, and Dipartimento di Chimica, \\ Università di Napoli "Federico II", Naples, 80126, Italy
}

Received: March 15, 2006; In Final Form: June 15, 2006

\begin{abstract}
We report the four diffusion coefficients for the lysozyme- $\mathrm{MgCl}_{2}$-water ternary system at $25{ }^{\circ} \mathrm{C}$ and $\mathrm{pH}$ 4.5. The comparison with previous results for the lysozyme- $\mathrm{NaCl}$-water ternary system is used to examine the effect of salt stoichiometry on the transport properties of lysozyme-salt aqueous mixtures. We find that the two cross-diffusion coefficients are very sensitive to salt stoichiometry. One of the cross-diffusion coefficients is examined in terms of common-ion, excluded-volume, and protein-preferential hydration effects. We use the four ternary diffusion coefficients to extract chemical-potential cross-derivatives and proteinpreferential interaction coefficients. These thermodynamic data characterize the protein-salt thermodynamic interactions. We demonstrate the presence of the common-ion effect (Donnan effect) by analyzing the dependence of the preferential-interaction coefficient not only with respect to salt concentration but also with respect to salt stoichiometry. We conclude that the common-ion effect and the protein-preferential hydration are both important for describing the lysozyme- $\mathrm{MgCl}_{2}$ thermodynamic interaction.
\end{abstract}

\section{Introduction}

The chemical potential of a protein component in aqueous solution is significantly affected by the presence of hydration, ligand binding, crowding, and Donnan effects. ${ }^{1-12}$ One way to modify these factors is by varying the concentration of additives in solution. As a result, conformational changes, ${ }^{2}$ protein precipitation, and protein crystallization may occur. ${ }^{10-12} \mathrm{Un}$ derstanding how the chemical potential of a protein is affected by the concentration of additives is important for (1) predicting conditions where phase transitions of protein solutions can occur and (2) understanding the mechanism of interaction between the protein and additives relevant to protein unfolding, ${ }^{2,13}$ enzyme catalysis, ${ }^{14}$ and ligand binding. ${ }^{15}$

Among all additives, salts are clearly the most employed in protein solutions. In small amounts $(<0.1 \mathrm{M})$, salts are used as buffer components and to reproduce physiological conditions. In larger amounts, they find important applications in protein crystallization, protein purification by precipitation, ${ }^{10}$ protein unfolding (e.g., guanidinium hydrochloride), ${ }^{16}$ and salt-induced activation of lyophilized enzymes in organic solvents. ${ }^{14}$

The effect of salt on the thermodynamics of protein solutions has been extensively studied, especially in relation to lysozyme$\mathrm{NaCl}$ aqueous systems. The second virial coefficient, $B_{2}$, determined by $\operatorname{light}^{17}$ and X-ray scattering, ${ }^{18}$ has been the primary parameter for investigating the action of salts on proteins. This parameter characterizes protein-protein net interactions in solutions. Although $B_{2}$ is very important in addressing the effect of salt type and concentration on proteinprotein interactions, it does not directly probe protein-salt interactions. This is an essential ingredient for explaining the effect of salt on the thermodynamics of protein solutions,

* To whom correspondence should be addressed. E-mail: O.Annunziata@tcu.edu. Telephone: (817) 257-6215. Fax: (817) 257-5851.

Texas Christian University.

‡ Università di Napoli "Federico II". especially at the high salt concentrations relevant to protein crystallization, precipitation, unfolding, and enzyme catalysis. To obtain a more complete description of the action of salt ions on proteins, experimental techniques that can directly probe protein-salt interactions must be employed. Equilibrium dialysis ${ }^{1}$ and vapor pressure osmosis ${ }^{3}$ has been used for determining the effect of salt concentration on the protein chemical potential, i.e., the first derivative of the protein chemical potential with respect to the salt concentration. Most of these results have been interpreted in terms of protein preferential hydration and/or binding of salt ions.

The dependence of the chemical potential of a macromolecule on salt concentration is also central for understanding diffusive mass transport of proteins. One consequence of this thermodynamic aspect is that a gradient of salt concentration can generate a gradient of protein chemical potential and vice versa. ${ }^{19}$ This implies that the diffusion of salt and protein are coupled. In the case of a ternary protein-saltwater solution, protein-salt coupled diffusion is described by a matrix of four diffusion coefficients. ${ }^{19-21}$ Clearly, this diffusion matrix can be used to probe protein-salt interactions.

Recently, we have introduced a novel method based on ternary diffusion measurements for determining the effect of salt concentration on the protein chemical potential. ${ }^{9,19} \mathrm{We}$ applied this method to lysozyme in the presence of three 1:1 electrolyte cases: $\mathrm{NaCl},{ }^{9} \mathrm{KCl},{ }^{19}$ and $\mathrm{NH}_{4} \mathrm{Cl}^{22}$ The precision of these extracted data allowed us to extract the first derivative of the protein chemical potential as a function of salt concentration. Using our results, we have determined two mechanisms of action of salts on lysozyme-salt interactions. The main mechanism of action is not preferential hydration but the common-ion effect, ${ }^{9}$ also known as the Donnan effect, ${ }^{23}$ which is commonly believed to become negligible for salt concentrations higher than $0.1 \mathrm{M}^{24} \mathrm{We}$ have found that the common-ion effect is significant at salt concentrations relevant to protein crystallization and precipitation $(0.2-1.5 \mathrm{M})$. Furthermore, the 
common-ion effect is essential for explaining the diffusion properties of lysozyme-salt solutions. ${ }^{9}$

We remark that the common-ion effect is intimately related to the salt stoichiometry. For this reason, it is very valuable to analyze the effect of 2:1 electrolytes on the thermodynamic and diffusion properties of lysozyme solutions. In this paper, we present the first study of lysozyme-salt coupled diffusion in the presence of a 2:1 electrolyte. We report ternary diffusion measurements on the lysozyme- $\mathrm{MgCl}_{2}$-water system at $25^{\circ} \mathrm{C}$ and $\mathrm{pH} 4.5$. Experiments were performed at $0.6 \mathrm{mM}(\approx 8.6$ $\mathrm{mg} / \mathrm{mL}$ ) lysozyme and $0.09-2.00 \mathrm{M} \mathrm{MgCl}_{2}$ concentrations. Our experimental results are compared here with those previously obtained for the lysozyme- $\mathrm{NaCl}$-water system. ${ }^{19,21}$ The central objective of this paper is to describe diffusion and thermodynamics of proteins in the presence of 2:1 electrolyte solutions by applying common-ion, excluded-volume, and preferentialhydration concepts.

\section{Ternary Diffusion Coefficients}

For the protein $(1)-\operatorname{salt}(2)-$ water $(0)^{25}$ ternary system, multicomponent diffusion is described by the extended Fick's first law: $20,21,26$

$$
\begin{aligned}
& -J_{1}=D_{11} \nabla C_{1}+D_{12} \nabla C_{2} \\
& -J_{2}=D_{21} \nabla C_{1}+D_{22} \nabla C_{2}
\end{aligned}
$$

Here, $C_{1}$ and $C_{2}$ are molar concentrations of the two solutes, $J_{1}$ and $J_{2}$ are the corresponding fluxes, and the four $D_{i j}$ 's (with $i, j$ $=1,2$ ) are the diffusion coefficients. Main-diffusion coefficients, $D_{11}$ and $D_{22}$, describe the flux of a solute due to its own concentration gradient, while cross-diffusion coefficients, $D_{12}$ and $D_{21}$, describe the flux of a solute due to the concentration gradient of the other solute.

Diffusion can be described relative to different reference frames. ${ }^{27}$ Thus eq 1a,b is applicable in volume-fixed (subscript V), solvent-fixed (subscript 0), and other frames. Diffusion coefficients are measured in the laboratory-fixed frame, which is an excellent approximation of the $\left(D_{i j}\right)_{\mathrm{V}}$ values in the volumefixed frame. The $\left(D_{i j}\right)_{0}$ values can be easily calculated from the $\left(D_{i j}\right)_{\mathrm{V}}$ values and the partial molar volumes, $\overline{\mathrm{V}}_{i}$, obtained from density measurements. ${ }^{28-30}$

From irreversible thermodynamics, the fundamental driving forces for diffusion are the chemical potential gradients of the mixture components. Thus, isothermal ternary diffusion can be described in terms of the Onsager diffusion coefficients (ODCs) $L_{i j}$ and the chemical potential gradients $\nabla \mu_{i}$. The corresponding linear laws are:

$$
\begin{aligned}
& -J_{1}=L_{11} \nabla \mu_{1}+L_{12} \nabla \mu_{2} \\
& -J_{2}=L_{21} \nabla \mu_{1}+L_{22} \nabla \mu_{2}
\end{aligned}
$$

In the solvent frame, the Onsager reciprocal relation $(\mathrm{ORR})^{28-31}$ is:

$$
\left(L_{12}\right)_{0}=\left(L_{21}\right)_{0}
$$

We can use eqs $1 \mathrm{a}, \mathrm{b}$ and $2 \mathrm{a}, \mathrm{b}$ in the solvent frame to relate the diffusion coefficients, $\left(D_{i j}\right)_{0}$, to the ODCs, $\left(L_{i f}\right)_{0}$, and the chemical potential derivatives, $\mu_{i j} \equiv\left(\left\{\partial \mu_{i}\right\} /\left\{\partial C_{j}\right\}\right)_{T, p, C_{k}, k \neq j}$, where $T$ is the temperature and $p$ the pressure:

$$
\begin{aligned}
& \left(D_{11}\right)_{0}=\left(L_{11}\right)_{0} \mu_{11}+\left(L_{12}\right)_{0} \mu_{21} \\
& \left(D_{12}\right)_{0}=\left(L_{11}\right)_{0} \mu_{12}+\left(L_{12}\right)_{0} \mu_{22} \\
& \left(D_{21}\right)_{0}=\left(L_{21}\right)_{0} \mu_{11}+\left(L_{22}\right)_{0} \mu_{21} \\
& \left(D_{22}\right)_{0}=\left(L_{21}\right)_{0} \mu_{12}+\left(L_{22}\right)_{0} \mu_{22}
\end{aligned}
$$

Using eq 3 and the equality of the molality-based chemicalpotential cross-derivatives, eq $4 \mathrm{a}-\mathrm{d}$ can be solved with respect to $\mu_{12}$ and $\mu_{21}$, yielding: ${ }^{19}$

$$
\begin{gathered}
\mu_{12}=\left[\mu_{11}\left[C_{1} \overline{\mathrm{V}}_{2}\left(D_{22}\right)_{0}-\left(1-C_{1} \overline{\mathrm{V}}_{1}\right)\left(D_{12}\right)_{0}\right]-\right. \\
\left.\mu_{22}\left[C_{2} \overline{\mathrm{V}}_{1}\left(D_{22}\right)_{0}-\left(1-C_{1} \overline{\mathrm{V}}_{1}\right)\left(D_{21}\right)_{0}\right]\right] / \\
{\left[\left(1-C_{2} \overline{\mathrm{V}}_{2}\right)\left(D_{22}\right)_{0}-\left(1-C_{1} \overline{\mathrm{V}}_{1}\right)\left(D_{11}\right)_{0}\right]} \\
\mu_{21}=\left[\mu_{11}\left[C_{1} \overline{\mathrm{V}}_{2}\left(D_{11}\right)_{0}-\left(1-C_{2} \overline{\mathrm{V}}_{2}\right)\left(D_{12}\right)_{0}\right]-\right. \\
\left.\mu_{22}\left[C_{2} \overline{\mathrm{V}}_{1}\left(D_{11}\right)_{0}-\left(1-C_{2} \overline{\mathrm{V}}_{2}\right)\left(D_{21}\right)_{0}\right]\right] / \\
{\left[\left(1-C_{2} \overline{\mathrm{V}}_{2}\right)\left(D_{22}\right)_{0}-\left(1-C_{1} \overline{\mathrm{V}}_{1}\right)\left(D_{11}\right)_{0}\right]}
\end{gathered}
$$

where the partial molar volumes, $\overline{\mathrm{V}}_{i}$, are expressed in $\mathrm{dm}^{3} \mathrm{~mol}^{-1}$.

We can express the chemical potential derivatives in terms of molar concentrations and mean ionic activity coefficients, $y_{i}$. If the stoichiometric coefficients for the cations (i.e., lysozyme and magnesium) is taken to be unity, we obtain the following relationships: ${ }^{31}$

$$
\begin{gathered}
\frac{\mu_{11}}{R T}=\frac{1}{C_{1}}+\frac{z_{\mathrm{p}}^{2}}{z_{\mathrm{p}} C_{1}+z_{\mathrm{M}} C_{2}}+\left(z_{\mathrm{p}}+1\right) \frac{\partial \ln y_{1}}{\partial C_{1}} \\
\frac{\mu_{12}}{R T}=\frac{z_{\mathrm{M}} z_{\mathrm{p}}}{z_{\mathrm{p}} C_{1}+z_{\mathrm{M}} C_{2}}+\left(z_{\mathrm{p}}+1\right) \frac{\partial \ln y_{1}}{\partial C_{2}} \\
\frac{\mu_{21}}{R T}=\frac{z_{\mathrm{M}} z_{\mathrm{p}}}{z_{\mathrm{p}} C_{1}+z_{\mathrm{M}} C_{2}}+\left(1+z_{\mathrm{M}}\right) \frac{\partial \ln y_{2}}{\partial C_{1}} \\
\frac{\mu_{22}}{R T}=\frac{1}{C_{2}}+\frac{z_{\mathrm{M}}{ }^{2}}{z_{\mathrm{p}} C_{1}+z_{\mathrm{M}} C_{2}}+\left(1+z_{\mathrm{M}}\right) \frac{\partial \ln y_{2}}{\partial C_{2}}
\end{gathered}
$$

where $z_{\mathrm{p}}$ and $z_{\mathrm{M}}$ are, respectively, the charge of the protein and the charge of the salt cation.

Parts a and b of eq 5 can be used to calculate $\mu_{12}$ and $\mu_{21}$ from the $\left(D_{i j}\right)_{0}$ 's and $\overline{\mathrm{V}}_{\mathrm{i}}$ 's and estimates of $\mu_{11}$ and $\mu_{22} .{ }^{19}$ The value of $\mu_{11}$ is obtained by neglecting the nonideal term $\left(z_{\mathrm{p}}+\right.$ $1)\left(\partial \ln y_{1} / \partial C_{1}\right)$ in eq $6 a$. The value of $z_{\mathrm{p}}$ can be initially set equal to that extracted by titration experiments. We will show in Results that we can obtain a more appropriate value of $z_{p}$ from our $\mu_{12}$ and $\mu_{21}$ results. We remark that our calculated values of $\mu_{12}$ and $\mu_{21}$ are rather insensitive to the accuracy of $\mu_{11}$ estimates; indeed, we find that a 5-fold change in $\mu_{11}$ values lead to an error of less than $5 \%$ in both $\mu_{12}$ and $\mu_{21}$. According to second-virial-coefficient estimates, the nonideal term is about $10 \%$ of the ideal term in $\mu_{11} \cdot{ }^{9}$ We thus conclude that more accurate estimates of $\mu_{11}$ are not necessary. The value of $\mu_{22}$ is obtained by taking $\left(z_{\mathrm{M}}+1\right)\left(\partial \ln y_{2} / \partial C_{2}\right)$ from the activitycoefficient data available on the binary salt-water systems. These estimates of $\mu_{22}$ can be considered accurate because the protein concentration is low. Indeed, the ternary salt main-diffusion coefficient, $\left(D_{22}\right)_{0}$, is only $1-2 \%$ lower than the corresponding binary value within our experimental concentration ranges. Moreover, this small difference is nearly independent of salt concentration. Thus we can relate it to the obstruction effect of proteins on salt diffusion rather than to changes in $\mu_{22} \cdot{ }^{9,19}$ 
TABLE 1: Ternary Diffusion Coefficients for the Lysozyme- $\mathrm{MgCl}_{2}-\mathrm{H}_{2} \mathrm{O}$ System at $25{ }^{\circ} \mathrm{C}$ and pH 4.5

\begin{tabular}{lllllll}
\hline$\overline{\bar{C}}_{1}(\mathrm{mM})$ & 0.5997 & 0.5992 & 0.5975 & 0.5987 & 0.5996 & 0.5996 \\
$\overline{\bar{C}}_{2}(\mathrm{M})$ & 0.0931 & 0.2326 & 0.4642 & 0.9304 & 1.5994 & 1.9995 \\
$\overline{\mathrm{V}}_{0}\left(\mathrm{~cm}^{3} \mathrm{~mol}^{-1}\right)$ & 18.076 & 18.058 & 18.050 & 18.015 & 17.930 & 17.874 \\
$\overline{\mathrm{V}}_{1}\left(\mathrm{~cm}^{3} \mathrm{~mol}^{-1}\right)$ & 10190 & 10240 & 10080 & 10230 & 10180 & 10200 \\
$\overline{\mathrm{V}}_{2}\left(\mathrm{~cm}^{3} \mathrm{~mol}^{-1}\right)$ & 17.36 & 19.31 & 20.89 & 23.11 & 26.63 & \\
$\left(D_{11}\right)_{\mathrm{v}}\left(10^{-9} \mathrm{~m}^{2} \mathrm{~s}^{-1}\right)$ & $0.1270 \pm 0.0002$ & $0.1145 \pm 0.0001$ & $0.1019 \pm 0.002$ & $0.0833 \pm 0.0002$ & $0.0640 \pm 0.0001$ & $0.0548 \pm 0.0002$ \\
$\left(D_{12}\right)_{\mathrm{v}}\left(10^{-12} \mathrm{~m}^{2} \mathrm{~s}^{-1}\right)$ & $0.799 \pm 0.008$ & $0.324 \pm 0.003$ & $0.201 \pm 0.007$ & $0.145 \pm 0.006$ & $0.156 \pm 0.004$ & $0.151 \pm 0.005$ \\
$\left(D_{21}\right)_{\mathrm{v}}\left(10^{-9} \mathrm{~m}^{2} \mathrm{~s}^{-1}\right)$ & $3.5 \pm 0.2$ & $4.4 \pm 0.1$ & $6.8 \pm 0.2$ & $12.3 \pm 0.2$ & $21.4 \pm 0.1$ \\
$\left(D_{22}\right)_{\mathrm{v}}\left(10^{-9} \mathrm{~m}^{2} \mathrm{~s}^{-1}\right)$ & $1.034 \pm 0.001$ & $1.025 \pm 0.001$ & $1.040 \pm 0.002$ & $1.080 \pm 0.002$ & $1.113 \pm 0.001$ & $1.102 \pm 0.001$ \\
$\left(D_{11}\right)_{0}\left(10^{-9} \mathrm{~m}^{2} \mathrm{~s}^{-1}\right)$ & 0.1278 & 0.1153 & 0.1026 & 0.0804 & 0.0648 & 0.0556 \\
$\left(D_{12}\right)_{0}\left(10^{-12} \mathrm{~m}^{2} \mathrm{~s}^{-1}\right)$ & 0.815 & 0.338 & 0.215 & 0.170 & 0.176 & 0.172 \\
$\left(D_{21}\right)_{0}\left(10^{-9} \mathrm{~m}^{2} \mathrm{~s}^{-1}\right)$ & 3.6 & 4.7 & 7.4 & 13.4 & 23.5 & 28.7 \\
$\left(D_{22}\right)_{0}\left(10^{-9} \mathrm{~m}^{2} \mathrm{~s}^{-1}\right)$ & 1.036 & 1.030 & 1.051 & 1.105 & 1.166 & 1.171
\end{tabular}

TABLE 2: Chemical Potential Derivatives and ODCs for the Lysozyme- $\mathrm{MgCl}_{2}-\mathrm{H}_{2} \mathrm{O}$ System

\begin{tabular}{cccccccc}
\hline$C_{2}(\mathrm{M})$ & $\begin{array}{r}\mu_{11} / R T \\
\left(\mathrm{M}^{-1}\right)\end{array}$ & $\begin{array}{r}\mu_{22} / R T \\
\left(\mathrm{M}^{-1}\right)\end{array}$ & $\begin{array}{r}\mu_{12} / R T \\
\left(\mathrm{M}^{-1}\right)\end{array}$ & $\begin{array}{r}\mu_{21} / R T \\
\left(\mathrm{M}^{-1}\right)\end{array}$ & $\begin{array}{c}R T\left(L_{11}\right)_{0} / C_{1} \\
\left(10^{-9} \mathrm{~m}^{2} \mathrm{~s}^{-1}\right)\end{array}$ & $\begin{array}{c}R T\left(L_{12}\right)_{0} / C_{1} \\
\left(10^{-9} \mathrm{~m}^{2} \mathrm{~s}^{-1}\right)\end{array}$ & $\begin{array}{c}R T\left(L_{22}\right)_{0} / C_{2} \\
\left(10^{-9} \mathrm{~m}^{2} \mathrm{~s}^{-1}\right)\end{array}$ \\
\hline 0.093 & 2003 & 27.303 & 77.1 & 103.5 & 0.220 & -0.29 & 0.413 \\
0.233 & 1805 & 11.924 & 28.3 & 56.9 & 0.144 & -0.22 & 0.373 \\
0.464 & 1742 & 6.938 & 17.3 & 49.8 & 0.105 & -0.21 & 0.327 \\
0.930 & 1705 & 4.714 & 12.9 & 57.8 & 0.088 & -0.24 & 0.178 \\
1.599 & 1688 & 4.111 & 16.7 & 83.4 & 0.076 & -0.23 & 0.144 \\
2.000 & 1684 & 4.076 & 17.9 & 100.6 & 0.069 &
\end{tabular}

The largest source of error in $\mu_{12}$ and $\mu_{21}$ comes from the uncertainty of the $\left(D_{21}\right)_{0}$ values. The uncertainty of $\mu_{21}$ is at least three times lower than that of $\mu_{12}$. A conservative estimation of the error of $\left(D_{21}\right)_{0}$ is $\pm 0.2 \times 10^{-9} \mathrm{~m}^{2} \mathrm{~s}^{-1}$ for all cases (see Table 1). On this basis, the uncertainty of $\mu_{12}$ in the lysozyme $-\mathrm{MgCl}_{2}$ experiments is $\approx 9 \%$ at $C_{2}=0.09 \mathrm{M}$ and drops to $\approx 4 \%$ at $C_{2}>1.0 \mathrm{M}$. We note that the uncertainty of $\mu_{12}$ in the $1: 1$ electrolyte systems was $2-3 \%$.

\section{Materials and Methods}

Materials. Six-times recrystallized and lyophilized egg-white lysozyme (HEWL) was purchased from Seikagaku America and used without further purification. ${ }^{21}$ A protein-water stock solution was prepared by weight using double-distilled water. The molecular weight of HEWL was taken to be $14307 \mathrm{~g}$ $\mathrm{mol}^{-1}$. Corrections were made for the chloride ion weight fraction in the HEWL samples as shown in ref 21. Mallinckrodt AR $\mathrm{MgCl}_{2} \cdot 6 \mathrm{H}_{2} \mathrm{O}$ was used without further purification. A $\mathrm{MgCl}_{2}$ - water stock solution was prepared and its density was carefully measured at $25^{\circ} \mathrm{C}$. This density value was used to calculate $\mathrm{MgCl}_{2}$ concentration from the available densityconcentration relation. ${ }^{31}$

Methods. The Gosting diffusiometer and its modifications, density measurements, solution preparation, $\mathrm{pH}$ adjustment, and data reduction procedures are described in our previous papers. ${ }^{19,21}$ In brief, solutions for diffusion measurements were prepared by adding known weights of lysozyme and $\mathrm{MgCl}_{2}$ stock solutions. Water was then used to dilute the solution almost to the final volume. The $\mathrm{pH}$ of the solution was then adjusted to 4.5 by using a few drops of a $\mathrm{HCl}$-water stock solution $(\mathrm{pH}$ 1.2). A Corning $135 \mathrm{pH}$ meter with an Orion 8102 ROSS combination $\mathrm{pH}$ electrode, standardized with Corning reference solutions, was used to measure the $\mathrm{pH}$. The final volume was then reached by adding water, and the $\mathrm{pH}$ remeasured to confirm its value of 4.5 .

Ternary mutual diffusion coefficients were measured at 25.00 ${ }^{\circ} \mathrm{C}$ with the Gosting diffusiometer operating in the Rayleigh interferometric optical mode. The instrument has been upgraded with a laser light source and a vertical linear $6 \mathrm{~cm} 6000$ pixel photodiode scanning array at the image position. A stepping motor moved the array horizontally across the Rayleigh inter- ferometric pattern and data were recorded at $10 \mu$ horizontal intervals. This gives the two-dimensional light-intensity distribution of the Rayleigh pattern, which yields the refractive-index profile inside the diffusion cell. We obtained 50 refractive-index profiles during the course of each experiment. Experiments were performed by the free-diffusion method in a $10 \mathrm{~cm}$ vertical diffusion cell with a $2.5 \mathrm{~cm}$ horizontal optical path length and a $0.3 \mathrm{~cm}$ width. The temperature was regulated to $\pm 0.001{ }^{\circ} \mathrm{C}$ precision and $\pm 0.01{ }^{\circ} \mathrm{C}$ accuracy. Initial step-function distributions of solute concentrations were prepared with the boundary located at the center of the cell. All experimental data were obtained before detectable concentration changes occurred at the top and bottom ends of the cell, consistent with the freediffusion boundary condition. A minimum of two experiments are required for determining the four diffusion coefficients at a given set of mean concentrations $\left(\overline{\bar{C}}_{1}, \overline{\bar{C}}_{2}\right.$ in Table 1). These two experiments must have different combinations of solute concentration differences across the diffusion boundary. To verify reproducibility, two other duplicate experiments were performed at each set of mean concentrations. More experimental details are available in the Supporting Information.

\section{Results}

In Table 1, we report the volume-fixed $\left(D_{i j}\right)_{\mathrm{V}}$ values calculated with data from all four experiments at each of the six $\mathrm{MgCl}_{2}$ concentrations. Table 1 also includes the partial molar volumes $\bar{V}_{0}, \bar{V}_{1}, \bar{V}_{2}$ obtained from density measurements. Solvent frame $\left(D_{i j}\right)_{0}$ are calculated from the $\left(D_{i j}\right)_{\mathrm{V}}$ and $\bar{V}_{i}$ by using eq 2 in ref 28. Tables with detailed results for each diffusion experiment are available in the Supporting Information.

In Table 2, we report the values of $\mu_{11} / R T$ and $\mu_{22} / R T$, obtained using the procedures described in the previous section, and the values of $\mu_{12} / R T$ and $\mu_{21} / R T$, obtained from eq $5 \mathrm{a}, \mathrm{b}$. Table 2 also includes $R T\left(L_{i j}\right)_{0}$ values calculated from eq $4 \mathrm{a}-\mathrm{d}$ (explicit relations are given by eq 7 in ref 19).

In Figure $1 \mathrm{a}-\mathrm{d}$, we show the four diffusion coefficients as functions of $C_{2}$ at $C_{1}=0.6 \mathrm{mM}$ for the $\mathrm{MgCl}_{2}$ case. For comparison, we include the previously reported $\left(D_{i j}\right)_{\mathrm{V}}$ values for the $\mathrm{NaCl}$ case $^{21}$ (at $\mathrm{pH} 4.5$ ). In Figure 1d, we include binary saltwater data ${ }^{32,33}$ (dashed curves) together with the $\left(D_{22}\right)_{\mathrm{V}}$ ternary results. 

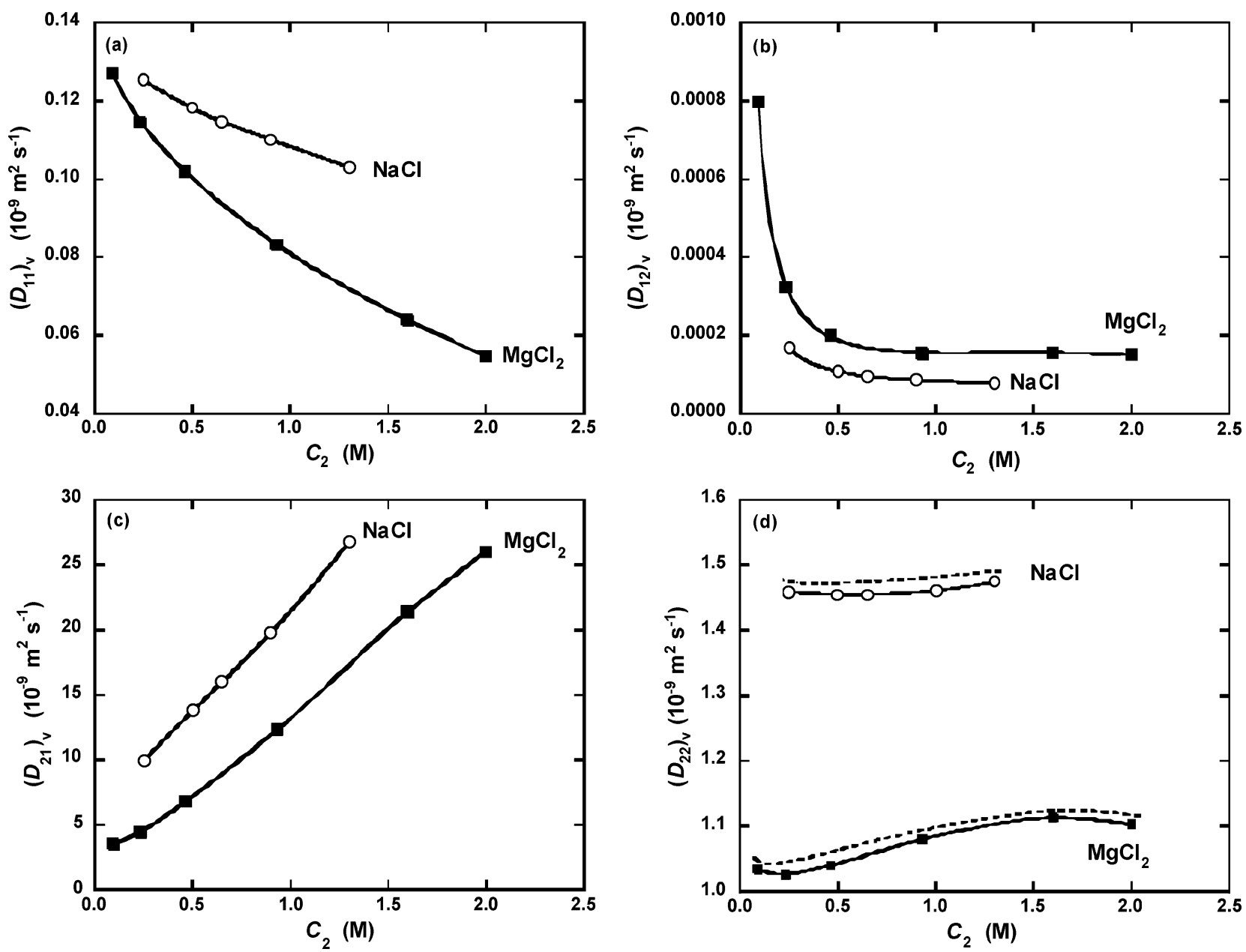

Figure 1. Volume-fixed diffusion coefficients as functions of salt concentration, $C_{2}$, for the lysozyme $-\mathrm{NaCl}-\mathrm{H}_{2} \mathrm{O}(\mathrm{O})$ and the lysozyme $-\mathrm{MgCl}_{2}-$ $\mathrm{H}_{2} \mathrm{O}$ (匹) systems at $C_{1}=0.6 \mathrm{mM}, \mathrm{pH} 4.5$, and $25^{\circ} \mathrm{C}$ : (a) $\left(D_{11}\right)_{\mathrm{V}}$, (b) $\left(D_{12}\right)_{\mathrm{V}}$, (c) $\left(D_{21}\right)_{\mathrm{V}}$, (d) $\left(D_{22}\right)_{\mathrm{V}}$. The solid curves are smoothed through the ternary experimental points. The dashed curves are smoothed through the omitted binary diffusion coefficients for the salt components; data taken from ref $33(\mathrm{NaCl})$ and ref 32 from the $\left(\mathrm{MgCl}_{2}\right)$.
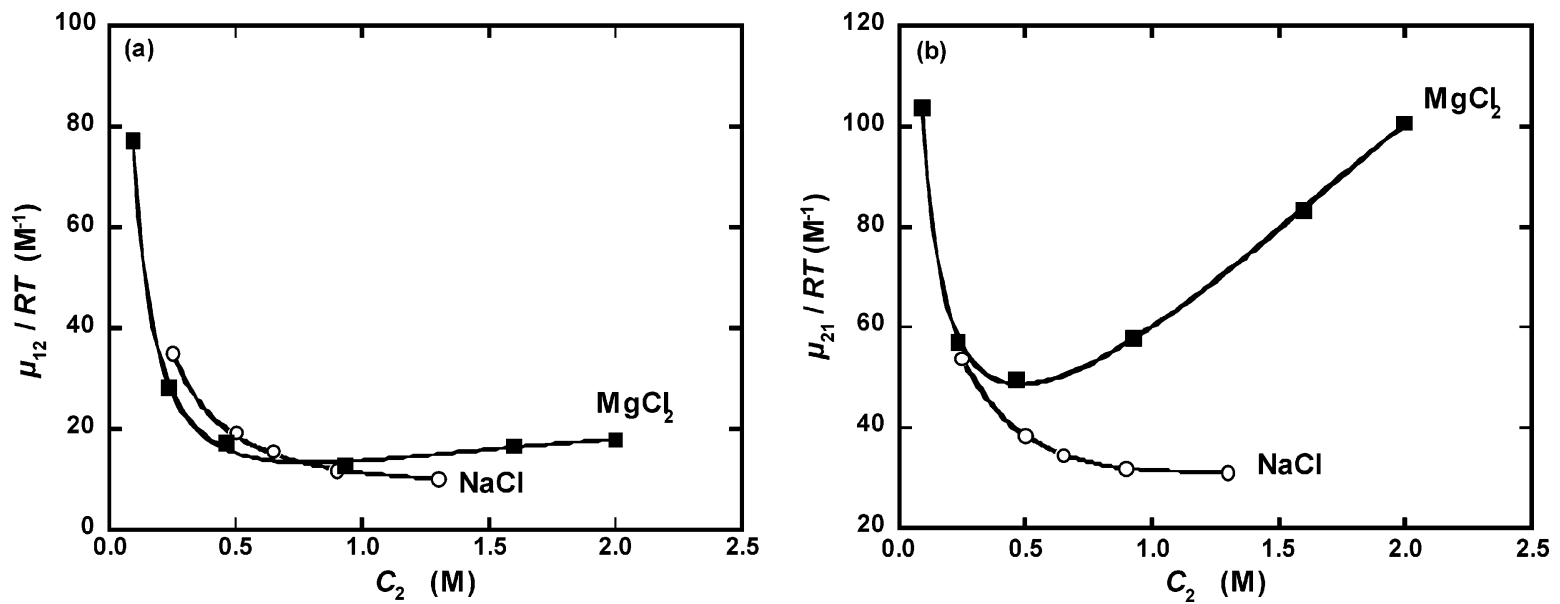

Figure 2. Chemical-potential cross-derivatives as a function of salt concentration, $C_{2}$, for the lysozyme- $\mathrm{NaCl}-\mathrm{H}_{2} \mathrm{O}(\mathrm{O})$ and the lysozyme$\mathrm{MgCl}_{2}-\mathrm{H}_{2} \mathrm{O}(\boldsymbol{\square})$ systems. The solid curves are fits to the data using eq $6 \mathrm{~b}$ for $\mu_{12} /(R T)$ and eq $6 \mathrm{c}$ for $\mu_{21} /(R T)$, where the activity-coefficient derivatives are expressed as polynomial functions of $C_{2}$.

In Figure 2a,b, we report $\mu_{12} / R T$ and $\mu_{21} / R T$ for the $\mathrm{MgCl}_{2}$ case as a function of salt concentration. In the same figure, we include our results for the $\mathrm{NaCl}$ case. ${ }^{19}$ At low salt concentrations, the values of $\mu_{12} / R T$ and $\mu_{21} / R T$ sharply decrease. This is consistent with eq 6b,c, in which $z_{\mathrm{p}} z_{\mathrm{M}} /\left(z_{\mathrm{p}} C_{1}+z_{\mathrm{M}} C_{2}\right)$ is a dominant term that varies approximately as $z_{\mathrm{p}} / C_{2}$. By expanding both activity coefficient derivatives as polynomial functions in $\left(z_{\mathrm{p}} C_{1}+z_{\mathrm{M}} C_{2}\right)$ and applying nonlinear regression to eq $6 \mathrm{~b}, \mathrm{c}$, we calculate experimental value of $z_{\mathrm{p}}=8 \pm 1$ for lysozyme in the aqueous lysozyme $-\mathrm{MgCl}_{2}$ mixtures. This is in agreement with the value of $z_{\mathrm{p}}=9 \pm 1$ we have previously obtained for $\mathrm{NaCl} .{ }^{19}$ The values of $z_{\mathrm{p}}$ obtained by fitting $\mu_{12} / R T$ and $\mu_{21} / R T$ correspond to the protein cation's effective charges, and they are lower than the experimental titration charges due to 
counterion binding. Because the titration charge is $\sim 11,{ }^{34}$ we estimate that $\sim 3$ chloride ions effectively move with one lysozyme molecule.

At high $\mathrm{MgCl}_{2}$ concentrations, both $\mu_{12} / R T$ and $\mu_{21} / R T$ increases with $C_{2}$. This behavior is not observed in the case of $\mathrm{NaCl}$. As we shall see later, the increase in $\mu_{12}$ and $\mu_{21}$ observed for $\mathrm{MgCl}_{2}$ is related to the strong nonideality behavior of the binary $\mathrm{MgCl}_{2}$-water system compared to the binary $\mathrm{NaCl}-$ water system.

\section{Discussion}

In this section, we will first review two important diffusion models used as references for interpreting our results. We will then examine the behavior of the four diffusion coefficients for the lysozyme $-\mathrm{MgCl}_{2}$ - water system and compare our results with those previously obtained for the lysozyme- $\mathrm{NaCl}$-water system. This will allow us to determine the effect of salt stoichiometry on the diffusion coefficients. Finally, we will discuss our findings on the protein-salt thermodynamic interactions. One important feature of our systems is that the molar concentration of lysozyme is significantly lower than the salt concentration, i.e., $z_{\mathrm{p}} C_{1} \ll z_{\mathrm{M}} C_{2}$. This condition will be used throughout our discussion.

Diffusion of charged macromolecules in the presence of an electrolyte solution can be discussed in terms of two important models: (a) the Nernst-Hartley equations, ${ }^{26}$ which apply to an ideal-dilute ternary solution with two ionic components, and (b) the Stokes-Einstein equation, ${ }^{23}$ which describes the tracer diffusion coefficient (or mobility) of macromolecules in the limit of $C_{1} \rightarrow 0$. For both models, the diffusion coefficients are independent of frame because they apply at infinite dilution.

Nernst-Hartley Equations. At infinite dilution, the four diffusion coefficients of two ionic components with a common ion are related to the ionic mobilities of the three constituent ionic species. Because of electrostatic coupling (i.e., electroneutrality), the three ionic species cannot move independently. This coupled transport is described by the Nernst-Hartley $(\mathrm{N}-$ H) equations.

For our ternary electrolyte system, the $\mathrm{N}-\mathrm{H}$ equations are:

$$
\begin{gathered}
D_{11}=\tilde{D}_{\mathrm{p}}\left[1+\frac{z_{\mathrm{p}}^{2} C_{1}}{\Delta}\left(\tilde{D}_{\mathrm{Cl}}-\tilde{D}_{\mathrm{p}}\right)\right] \\
D_{12}=\tilde{D}_{\mathrm{p}} \frac{z_{\mathrm{p}} z_{\mathrm{M}} C_{1}}{\Delta}\left(\tilde{D}_{\mathrm{Cl}}-\tilde{D}_{\mathrm{M}}\right) \\
D_{21}=\tilde{D}_{\mathrm{M}} \frac{z_{\mathrm{p}} z_{\mathrm{M}} C_{2}}{\Delta}\left(\tilde{D}_{\mathrm{Cl}}-\tilde{D}_{\mathrm{p}}\right) \\
D_{22}=\tilde{D}_{\mathrm{M}}\left[1+\frac{z_{\mathrm{M}}{ }^{2} C_{2}}{\Delta}\left(\tilde{D}_{\mathrm{Cl}}-\tilde{D}_{\mathrm{M}}\right)\right]
\end{gathered}
$$

where $\Delta=z_{\mathrm{p}} C_{1}\left(z_{\mathrm{p}} \tilde{D}_{\mathrm{p}}+\tilde{D}_{\mathrm{Cl}}\right)+z_{\mathrm{M}} C_{2}\left(z_{\mathrm{M}} \tilde{D}_{\mathrm{M}}+\tilde{D}_{\mathrm{Cl}}\right)$. In eq $7 \mathrm{a}-$ $\mathrm{d}, \tilde{D}_{\mathrm{p}}, \tilde{D}_{\mathrm{M}}$, and $\tilde{D}_{\mathrm{Cl}}$ are, respectively, the tracer diffusion coefficients of the protein cation, salt co-ion $\left(\mathrm{Na}^{+}, z_{\mathrm{M}}=1\right.$; $\mathrm{Mg}^{2+}, \mathrm{z}_{\mathrm{M}}=2$ ), and chloride ion (common ion). The value of $\tilde{D}_{\mathrm{p}}=0.132 \times 10^{-9} \mathrm{~m}^{2} \mathrm{~s}^{-1}$ for lysozyme (in aqueous $\mathrm{NaCl}$ at $\mathrm{pH} 4.5$ ) was taken from ref 34 . The tracer diffusion coefficients for small ions have been calculated from limiting ionic mobilities. For $\mathrm{Na}^{+}, \mathrm{Mg}^{2+}$, and $\mathrm{Cl}^{-}$, they are $1.33,0.706$, and $2.03 \times 10^{-9} \mathrm{~m}^{2} \mathrm{~s}^{-1}$, respectively. ${ }^{35,36}$

We are interested in the case where $z_{\mathrm{p}} C_{1} \ll z_{\mathrm{M}} C_{2}$. Because $\tilde{D}_{\mathrm{p}}<\tilde{D}_{\mathrm{M}}, \tilde{D}_{\mathrm{Cl}}$, we can write $\Delta=z_{\mathrm{M}} C_{2}\left(z_{\mathrm{M}} \tilde{D}_{\mathrm{M}}+\tilde{D}_{\mathrm{Cl}}\right)$. Thus, eq $7 \mathrm{a}-\mathrm{d}$, which now apply under the conditions of $C_{2} \rightarrow 0$ and $z_{\mathrm{p}} C_{1} \ll z_{\mathrm{M}} C_{2}$, become:

$$
\begin{gathered}
D_{11}=\tilde{D}_{\mathrm{p}}\left(1+\frac{z_{\mathrm{p}}^{2} C_{1}}{z_{\mathrm{M}} C_{2}} \frac{\tilde{D}_{\mathrm{Cl}}-\tilde{D}_{\mathrm{p}}}{z_{\mathrm{M}} \tilde{D}_{\mathrm{M}}+\tilde{D}_{\mathrm{Cl}}}\right) \\
D_{12}=\tilde{D}_{\mathrm{p}} \frac{z_{\mathrm{p}} C_{1}}{C_{2}} \frac{\tilde{D}_{\mathrm{Cl}}-\tilde{D}_{\mathrm{M}}}{z_{\mathrm{M}} \tilde{D}_{\mathrm{M}}+\tilde{D}_{\mathrm{Cl}}} \\
D_{21}=z_{\mathrm{p}} \frac{\tilde{D}_{\mathrm{M}}\left(\tilde{D}_{\mathrm{Cl}}-\tilde{D}_{\mathrm{p}}\right)}{z_{\mathrm{M}} \tilde{D}_{\mathrm{M}}+\tilde{D}_{\mathrm{Cl}}} \\
D_{22}=\left(z_{\mathrm{M}}+1\right) \frac{\tilde{D}_{\mathrm{M}} \tilde{D}_{\mathrm{Cl}}}{z_{\mathrm{M}} \tilde{D}_{\mathrm{M}}+\tilde{D}_{\mathrm{Cl}}}
\end{gathered}
$$

Compared to eq $7 \mathrm{a}-\mathrm{d}$, eq $8 \mathrm{a}-\mathrm{d}$ has the advantage of showing the dominant forms of dependence of the four diffusion coefficients on the salt concentration and stoichiometry (i.e., $z_{\mathrm{M}}$ ).

Although the $\mathrm{N}-\mathrm{H}$ equations are only exact in the limits of both $C_{1}$ and $C_{2}$ approaching zero, they still provide an important reference tool for interpreting our experimental results. Because of their dependence on salt stoichiometry, the $\mathrm{N}-\mathrm{H}$ equations are especially valuable when we will discuss the effect of salt type on the two cross-diffusion coefficients.

Stokes-Einstein Equation. At infinite dilution, the protein tracer diffusion coefficient, $\tilde{D}_{\mathrm{p}}$, is often interpreted using the Stokes-Einstein equation: $\tilde{D}_{\mathrm{p}}=k_{\mathrm{B}} T /\left(6 \pi r_{\mathrm{H}}^{\mathrm{eq}} \eta\right)$, where $k_{\mathrm{B}}$ is Boltzmann's constant, $r_{\mathrm{H}}^{\mathrm{eq}}$ is the equivalent hydrodynamic radius, and $\eta$ is the viscosity of the surrounding fluid, i.e., the interstitial saltwater medium. ${ }^{23}$ As the salt concentration increases, viscosity increases for both the $\mathrm{NaCl}$ and $\mathrm{MgCl}_{2}$ cases, and $\tilde{D}_{\mathrm{p}}$ decreases. Because $D_{11}$ and $D_{12}$ are directly proportional to $\tilde{D}_{\mathrm{p}}$ according to eq $8 \mathrm{a}, \mathrm{b}$, we will use the Stokes-Einstein equation to assess the role of viscosity on the observed dependence of these two diffusion coefficients on salt type and concentration.

We will now examine each ternary diffusion coefficient. Because our thermodynamic results were obtained from the solvent-frame diffusion coefficients, we will address in particular the behavior of the $\left(D_{i j}\right)_{0}$ 's. Yet the difference between the values of $\left(D_{i j}\right)_{\mathrm{V}}$ and $\left(D_{i j}\right)_{0}$ is small and irrelevant for the interpretations reported below.

Examination of $\boldsymbol{D}_{\mathbf{1 1}}$. Values of $\left(D_{11}\right)_{\mathrm{V}}$ for the lysozyme$\mathrm{MgCl}_{2}$ and lysozyme- $\mathrm{NaCl}$ systems are shown in Figure 1a. In the $\mathrm{MgCl}_{2}$ case, the diffusion coefficient $D_{11}$ (i.e., $\left(D_{11}\right)_{\mathrm{V}}$ and $\left.\left(D_{11}\right)_{0}\right)$ significantly decreases as the salt concentration increases. At $C_{2}=2.0 \mathrm{M}, D_{11}$ reduces to $\approx 50 \%$ of its value at $0.09 \mathrm{M}$. In the case of $\mathrm{NaCl}$, this decrease is significantly smaller.

The observed behavior of $D_{11}$ for both salts can be ascribed to at least two factors. According to the Stokes-Einstein equation and eq $8 \mathrm{a}$, we expect the $D_{11}$ values to decrease as solution viscosity increases. To examine this effect, we consider the product $\left(D_{11}\right)_{0}\left(\eta / \eta_{0}\right)$, where $\eta$ is the viscosity of the corresponding binary saltwater systems $s^{37,38}$ and $\eta_{0}$ is the viscosity of water. In Figure 3, we plot $\left(D_{11}\right)_{0}\left(\eta / \eta_{0}\right)$ as a function of $C_{2}$. Clearly, this viscosity correction removes much of the $D_{11}$ dependence on salt type and concentration. We have previously shown that this applies to the $\mathrm{KCl}$ and $\mathrm{NH}_{4} \mathrm{Cl}$ cases as well. ${ }^{9}$

From Figure 3, we can see that, at low salt concentration, $\left(D_{11}\right)_{0}\left(\eta / \eta_{0}\right)$ decreases as $C_{2}$ increases for both salts. This result can be explained by analyzing eq $8 \mathrm{a}$, which shows that $D_{11}$ decreases as $C_{2}$ increases. This behavior is related to the electrostatic dragging effect of the faster chloride ions exerted on the positively charged proteins. Indeed, we have previously 


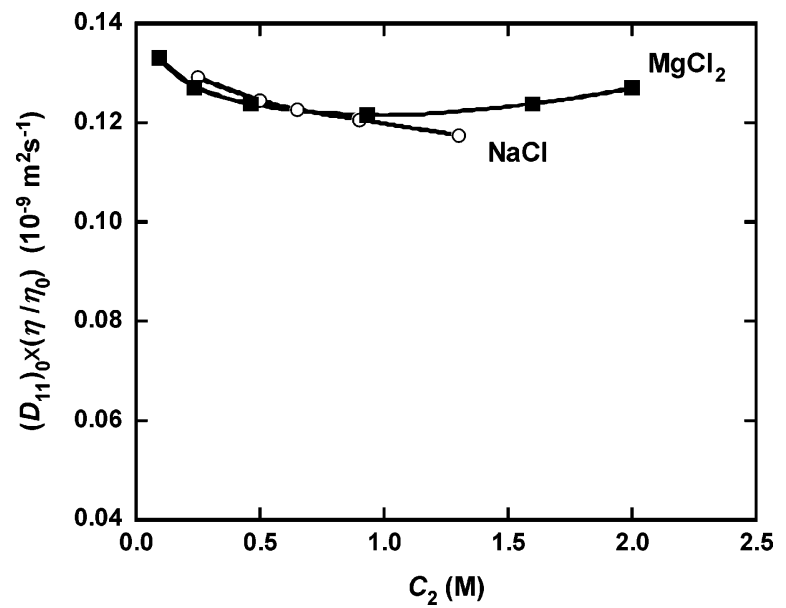

Figure 3. Viscosity-corrected $\left(D_{11}\right)_{0}\left(\eta / \eta_{0}\right)$ as a function of salt concentration, $C_{2}$, for the lysozyme $-\mathrm{NaCl}-\mathrm{H}_{2} \mathrm{O}(\mathrm{O})$ and the lysozyme$\mathrm{MgCl}_{2}-\mathrm{H}_{2} \mathrm{O}(\boldsymbol{\square})$ systems. The solid curves are smoothed through the ternary experimental points.

reported that the diffusion coefficient of the lysozyme chloride component in pure water $\left(0.54 \times 10^{-9} \mathrm{~m}^{2} \mathrm{~s}^{-1}\right.$ at $\left.\mathrm{pH} 4.5\right)$ is about four times higher than the lysozyme tracer diffusion coefficient. ${ }^{19,21}$ As the salt concentration increases, this dragging effect diminishes due to the presence of co-ion electrostatic shielding.

To emphasize the dependence of $D_{11}$ on concentration, we rewrite eq $8 \mathrm{a}$ as $D_{11}=\tilde{D}_{\mathrm{P}}\left(1+\alpha\left(C_{1} / C_{2}\right)\right)$. If we use the abovereported tracer diffusion coefficients, we estimate $\alpha=46$ for the $\mathrm{MgCl}_{2}$ case and $\alpha=18$ for the $\mathrm{NaCl}$ case, thereby implying that, at a given salt concentration, $D_{11}$ for the $\mathrm{MgCl}_{2}$ case is higher than $D_{11}$ for the $\mathrm{NaCl}$ case. This is indeed what we observe at low salt concentration $\left(C_{2} \leq 0.5 \mathrm{M}\right.$ in Figure 3$)$. At high salt concentration, the interpretation of the specific behavior of $\left(D_{11}\right)_{0}\left(\eta / \eta_{0}\right)$ becomes more difficult and needs to take into account protein conformational changes and specific effects of salt ions on protein-protein interactions. Assuming that hydrodynamic-radius changes can be ignored, our results at high salt concentrations suggest an increase of $\mu_{11}$ and a corresponding increase of protein-protein repulsive interactions. The presence of protein-protein repulsive interactions for lysozyme at high $\mathrm{MgCl}_{2}$ concentrations has previously been argued by Grygsby et al. ${ }^{39}$ using dynamic light scattering.

Examination of $\boldsymbol{D}_{22}$. Values of $\left(D_{22}\right)_{\mathrm{V}}$ for the lysozyme$\mathrm{MgCl}_{2}$ and lysozyme- $\mathrm{NaCl}$ systems are shown in Figure 1d. The ternary $D_{22}$ values are just $1-2 \%$ lower than the corresponding binary values. As mentioned earlier, this implies that our estimates of $\mu_{22}$ from binary activity coefficients are highly accurate. The small difference between the ternary and binary values is consistent with an expected small obstruction effect of the protein macromolecules on the motion of the small salt ions.

Examination of $\boldsymbol{D}_{12}$. Values of $\left(D_{12}\right)_{\mathrm{V}}$ for the lysozyme$\mathrm{MgCl}_{2}$ and lysozyme- $\mathrm{NaCl}$ systems are shown in Figure $1 \mathrm{~b}$. This cross-diffusion coefficient describes how the flux of lysozyme is affected by the salt concentration gradient. From Figure $1 \mathrm{~b}$, we can see that, at the low concentrations, $D_{12}$ decreases significantly as $C_{2}$ increases for both salts. This behavior can be qualitatively understood from the $\mathrm{N}-\mathrm{H}$ equations. In the presence of a gradient of salt concentration, a flux of both chloride and metal ions is generated. Because $\tilde{D}_{\mathrm{Cl}}$ $>\tilde{D}_{\mathrm{M}}$, the chloride ions will electrostatically drag both the positively charged proteins and the metal ions depending on their relative amounts: $C_{1} / C_{2}$. This is the reason $D_{12}$ is inversely

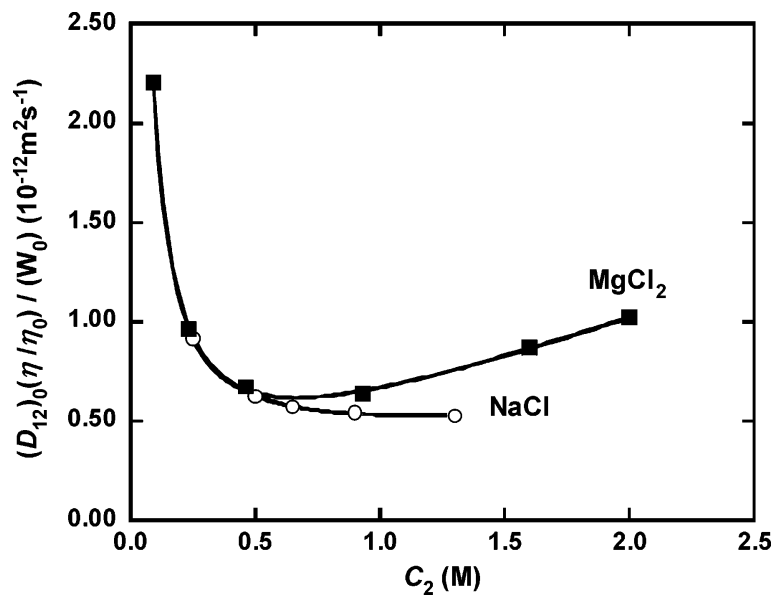

Figure 4. Corrected cross-diffusion coefficient $\left(D_{12}\right)_{0}\left(\eta / \eta_{0}\right) / W_{0}$ as a function of salt concentration, $C_{2}$, for the lysozyme $-\mathrm{NaCl}-\mathrm{H}_{2} \mathrm{O}(\mathrm{O})$ and the lysozyme $-\mathrm{MgCl}_{2}-\mathrm{H}_{2} \mathrm{O}$ (ם) systems. The solid curves are smoothed through the ternary experimental points.

proportional to $C_{2}$ and directly proportional to $\tilde{D}_{\mathrm{Cl}}-\tilde{D}_{\mathrm{M}}$. From the values of the tracer diffusion coefficients listed above, it is expected that $D_{12}$ will be larger for $\mathrm{MgCl}_{2}$ than for $\mathrm{NaCl}$ at a given salt concentration. This is consistent with our experimental results (see Figure 1b). Nevertheless, we observe that the $\mathrm{N}-\mathrm{H}$ equations poorly predict the experimental values of $D_{12}$ even at low salt concentration.

From Table 2 , we also note that $\left(L_{11}\right)_{0} \mu_{12} \approx-\left(L_{12}\right)_{0} u_{22},{ }^{9}$ which implies that $D_{12}$ is a small difference between two larger contributions (see eq $4 \mathrm{~b}$ ). This indicates that the prediction of $D_{12}$ from estimates of the Onsager diffusion coefficients is also difficult. Nonetheless, we can still attempt to understand the effect of salt type on $D_{12}$ by rearranging eq $4 \mathrm{~b}$ in the form of the following product: ${ }^{9}$

$$
\left(D_{12}\right)_{0}=\left(L_{11}\right)_{0} u_{12} W
$$

where

$$
W=1+\frac{\left(L_{12}\right)_{0}}{\left(L_{11}\right)_{0}} \frac{\mu_{22}}{\mu_{12}}
$$

In the limit, where $C_{2} \rightarrow 0$ and $C_{1} / C_{2} \rightarrow 0$, we can use eq 28 of ref 40 with the limiting values to obtain

$$
W_{0}=\frac{\tilde{D}_{\mathrm{Cl}}-\tilde{D}_{\mathrm{M}}}{z_{\mathrm{M}} \tilde{D}_{\mathrm{M}}+\tilde{D}_{\mathrm{Cl}}}
$$

The mobility ratio, $W_{0}$, and the viscosity correction, $\left(\eta / \eta_{0}\right)$, are the only two properties that directly depend on the type of saltwater binary system. We remove these factors by computing a corrected diffusion coefficient, $\left(D_{12}\right)_{0}\left(\eta / \eta_{0}\right) / W_{0}$, for both salt cases. According to $\mathrm{N}-\mathrm{H}$ equations and Stokes-Einstein equation, $\left(D_{12}\right)_{0}\left(\eta / \eta_{0}\right) / W_{0}$ should not depend on salt type. From Figure 4, we can see that there is virtually no detectable difference between the two salt cases at $C_{2}<0.5 \mathrm{M}$. At high salt concentration, we find that $\left(D_{12}\right)_{0}\left(\eta / \eta_{0}\right) / W_{0}$ for the $\mathrm{MgCl}_{2}$ case increases with $C_{2}$ contrary to what we observe for $\mathrm{NaCl}$. Although the observed difference is of difficult interpretation, we note that, according to eq $9,\left(D_{12}\right)_{0}$ is proportional to $\mu_{12}$. We indeed observe that the difference in the behavior of $\left(D_{12}\right)_{0}\left(\eta / \eta_{0}\right) / W_{0}$ at high $C_{2}$ may be assigned to the corresponding difference in the behavior of $\mu_{12}$ shown in Figure $2 \mathrm{a}$. 
TABLE 3: Thermodynamic Parameters for the Lysozyme- $\mathrm{NaCl}-\mathrm{H}_{2} \mathrm{O}$ System

\begin{tabular}{ccrccc}
\hline$C_{2}(\mathrm{M})$ & $\left(D_{21}\right)_{0} /\left(D_{22}\right)_{0}$ & $\mu_{21} / \mu_{22}$ & $-\Gamma_{\mu_{2}}$ & $\begin{array}{c}\mu_{12}{ }^{m} / R T \\
\left(\mathrm{~kg} \mathrm{~mol}^{-1}\right)\end{array}$ & $\begin{array}{c}\mu_{22}{ }^{m} / R T \\
\left(\mathrm{~kg} \mathrm{~mol}^{-1}\right)\end{array}$ \\
\hline 0.250 & 7.02 & 7.39 & 4.82 & 34.3 & 7.14 \\
0.500 & 9.87 & 10.28 & 5.14 & 18.7 & 3.63 \\
0.650 & 11.53 & 11.87 & 5.28 & 14.9 & 2.83 \\
0.900 & 14.24 & 14.61 & 5.41 & 11.3 & 2.09 \\
1.300 & 19.06 & 19.43 & 6.31 & 9.5 & 1.51
\end{tabular}

TABLE 4: Thermodynamic Parameters for the Lysozyme- $\mathrm{MgCl}_{2}-\mathrm{H}_{2} \mathrm{O}$ System

\begin{tabular}{cccccc}
\hline$C_{2}(\mathrm{M})$ & $\left(D_{21}\right)_{0} /\left(D_{22}\right)_{0}$ & $\mu_{21} / \mu_{22}$ & $-\Gamma_{\mu_{2}}$ & $\begin{array}{c}\mu_{12}{ }^{m} / R T \\
\left(\mathrm{~kg} \mathrm{~mol}^{-1}\right)\end{array}$ & $\begin{array}{c}\mu_{22}{ }^{m} / R T \\
\left(\mathrm{~kg} \mathrm{~mol}^{-1}\right)\end{array}$ \\
\hline 0.0931 & 3.5 & 3.8 & 2.82 & 76.2 & 27.0 \\
0.2326 & 4.6 & 4.8 & 2.37 & 27.8 & 11.7 \\
0.4642 & 7.0 & 7.2 & 2.49 & 16.7 & 6.7 \\
0.9304 & 12.1 & 12.3 & 2.74 & 12.2 & 4.5 \\
1.5994 & 20.2 & 20.3 & 4.06 & 15.3 & 3.8 \\
1.9995 & 24.5 & 24.7 & 4.39 & 15.9 & 3.6
\end{tabular}

Examination of $\boldsymbol{D}_{\mathbf{2 1}}$. Values of $\left(D_{21}\right)_{\mathrm{V}}$ for the lysozyme$\mathrm{MgCl}_{2}$ and lysozyme- $\mathrm{NaCl}$ systems are shown in Figure 1c. The $D_{21}$ values are large and increase with salt concentration. This implies a significant flux of salt due to the concentration gradient of the protein component. One contribution to the value of $D_{21}$ is related to the polyelectrolyte nature of the protein, which is included in the $\mathrm{N}-\mathrm{H}$ equations. In the presence of a gradient of lysozyme chloride, a flux of both chloride and lysozyme ions is generated. Because $\tilde{D}_{\mathrm{Cl}} \gg \tilde{D}_{\mathrm{p}}$, the chloride ions will electrostatically drag the metal ions, yielding a net flux of the salt component and a corresponding positive value of $D_{21}$. Because the salt component is present in large excess, $D_{21}$ should not depend on $C_{2}$ according to $\mathrm{N}-\mathrm{H}$ equations. Interestingly, contrary to $\mathrm{N}-\mathrm{H}$ prediction, we observe that $D_{21}$ significantly increases with $C_{2}$ well above the constant values predicted by eq $8 \mathrm{c}$. This occurs because a significant contribution to the value of $D_{21}$ can be related to excluded volume effects. ${ }^{9,19,41}$ In a solution in which the salt component has a uniform stoichiometric concentration $C_{2}$, the presence of protein macromolecules, treated as a second phase, produces an increase in salt concentration in the interstitial volume surrounding them. This interstitial concentration will increase as the protein concentration increases. Therefore, a gradient of $C_{1}$ will produce an "effective gradient" of salt in the same direction, leading to a positive contribution to the values of $D_{21}$.

We further observe that the values of $D_{21}$ for $\mathrm{NaCl}$ are higher than those for $\mathrm{MgCl}_{2}$. This is consistent with the $\mathrm{N}-\mathrm{H}$ prediction that $D_{21}$ is proportional to $\tilde{D}_{\mathrm{M}} /\left(z_{\mathrm{M}} \tilde{D}_{\mathrm{M}}+\tilde{D}_{\mathrm{Cl}}\right)$. We shall now explain the observed dependence of $D_{21}$ on salt type and concentration by examining the ratio $\left(D_{21}\right)_{0} /\left(D_{22}\right)_{0}$.

Examination of the Ratio $\left(\boldsymbol{D}_{21}\right)_{0} /\left(\boldsymbol{D}_{22}\right)_{0}$. According to $\mathrm{N}-\mathrm{H}$ equations, the ratio $D_{21} / D_{22}$ is equal to $\left[z_{\mathrm{p}} /\left(z_{\mathrm{M}}+1\right)\right] /\left(\tilde{D}_{\mathrm{Cl}}-\right.$ $\left.\left.\tilde{D}_{\mathrm{p}}\right) / \tilde{D}_{\mathrm{Cl}}\right]$ and independent of $\tilde{D}_{\mathrm{M}}$. Because $\left[\left(\tilde{D}_{\mathrm{Cl}}-\tilde{D}_{\mathrm{p}}\right) / \tilde{D}_{\mathrm{Cl}}\right]=$ 0.935 , we can neglect $\tilde{D}_{\mathrm{p}}$ and approximately write: $D_{21} / D_{22} \approx$ $z_{\mathrm{p}} /\left(z_{\mathrm{M}}+1\right)$, with $D_{21} / D_{22}$ slightly smaller than $z_{\mathrm{p}} /\left(z_{\mathrm{M}}+1\right)$. We also note that, in the limit of $C_{2} \rightarrow 0$ and $z_{\mathrm{p}} C_{1} \ll z_{\mathrm{M}} C_{2}$, we have: $\mu_{12} / \mu_{22}=\mu_{21} / \mu_{22}=z_{\mathrm{p}} /\left(z_{\mathrm{M}}+1\right)$. This result, together with eq $4 \mathrm{c}, \mathrm{d}$, suggests a direct relation between $\left(D_{21}\right)_{0} /\left(D_{22}\right)_{0}$ and $\mu_{21} / \mu_{22}$. From our data in Tables 3 and 4, we indeed observe that

$$
\frac{\left(D_{21}\right)_{0}}{\left(D_{22}\right)_{0}} \approx \frac{\mu_{21}}{\mu_{22}}
$$

with $\left(D_{21}\right)_{0} /\left(D_{22}\right)_{0}$ slightly smaller than $\mu_{21} / \mu_{22}$. This implies that

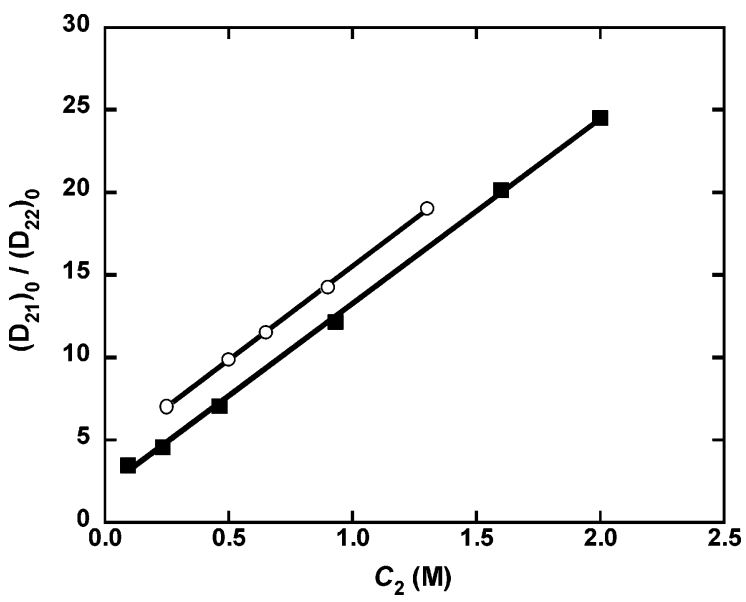

Figure 5. The quotient $\left(D_{21}\right)_{0} /\left(D_{22}\right)_{0}$ as a function of salt concentration, $C_{2}$, for the lysozyme $-\mathrm{NaCl}-\mathrm{H}_{2} \mathrm{O}(\mathrm{O})$ and the lysozyme $-\mathrm{MgCl}_{2}-\mathrm{H}_{2} \mathrm{O}$ (ם) systems. Straight lines fit through the data.

the ratio $\left(D_{21}\right)_{0} /\left(D_{22}\right)_{0}$ can be used to directly probe the system thermodynamics. Indeed this ratio is essentially a thermodynamic property. This important result is related to the relatively low mobility of proteins. That is, we can approximately describe our system as one in which the lysozyme molecules occupy fixed positions and the fast salt ions partition between high and low protein concentration. When the salt component (and the solvent) reaches equilibrium ( $\mu_{2}$ constant) within this "fixed" gradient of protein, we have $\left(J_{2}\right)_{0}=0$. Then, according to eq $1 \mathrm{~b}$, this gives $\left(D_{21}\right)_{0} /\left(D_{22}\right)_{0}=-\left(\partial C_{2} / \partial C_{1}\right)_{\mu_{2}}=\mu_{21} / \mu_{22}$, consistent with our findings. This argument shows the direct relation of the diffusion method used here to determine thermodynamic quantities and the more traditional equilibrium-dialysis experimental method. In the latter case, the salt partitions ( $\mu_{2}$ constant) between two domains of different protein concentrations separated by a membrane that does not allow the protein to diffuse through. It is important to remark that we do use the rigorous eq $5 \mathrm{a}, \mathrm{b}$ to determine the ratio $\mu_{21} / \mu_{22}$. Yet, the above discussion gives the rationale on why ternary diffusion is valuable in determining protein-salt thermodynamic interactions.

In Figure 5, we report the $\left(D_{21}\right)_{0} /\left(D_{22}\right)_{0}$ for $\mathrm{NaCl}$ and $\mathrm{MgCl}_{2}$ as a function of $C_{2}$. The curves appear to be approximately linear and nearly parallel but with different intercepts (i.e., values at $C_{2}=0$ with $z_{\mathrm{p}} C_{1} \ll z_{\mathrm{M}} C_{2}$ ). The difference in the intercept between $\mathrm{NaCl}$ and $\mathrm{MgCl}_{2}$ can be assigned to the difference in $z_{\mathrm{M}}$. Because $\left(D_{21}\right)_{0} /\left(D_{22}\right)_{0} \approx z_{\mathrm{p}} /\left(z_{\mathrm{M}}+1\right)$ at $C_{2}=0$, we predict the ratio of the $\mathrm{NaCl}$ to the $\mathrm{MgCl}_{2}$ intercepts to be $\approx 3 / 2$, assuming that $z_{\mathrm{p}}$ is independent of the type of salt.

To understand the dependence of $\left(D_{21}\right)_{0} /\left(D_{22}\right)_{0}$ on $C_{2}$, we will now consider an excluded-volume model.

The Excluded-Volume Model. This model considers the protein molecules as a second phase not accessible to the small salt ions. This excluded-volume effect produces an increase of small-ion concentration by a factor $1 /\left(1-C_{\mathrm{p}} V_{\mathrm{ex}}\right)$, where $C_{\mathrm{p}}$ is the protein concentration and $V_{\mathrm{ex}}$ is the excluded volume per each mole of protein. We assume that the excluded volume is constant and independent of salt concentration, and consider the case of $C_{1} \rightarrow 0$ so that we can ignore changes in excludedvolume properties due to protein-protein contacts. We also assume that the charge on the protein is constant.

Although the model is a simplification of actual systems, it yields a useful description of our thermodynamic results. According to the excluded volume model, the chemical potential of the salt component becomes 
$\left(\mu_{2}-\mu_{2}{ }^{0}\right) / R T=\ln C_{\mathrm{M}}^{\mathrm{int}}+z_{\mathrm{M}} \ln C_{\mathrm{Cl}}^{\mathrm{int}}+\left(z_{\mathrm{M}}+1\right) \ln y_{2}{ }^{\mathrm{int}}$

where the interstitial (int) ion concentrations are defined by

$$
\begin{gathered}
C_{\mathrm{Cl}}^{\mathrm{int}}=\frac{C_{\mathrm{Cl}}}{1-C_{\mathrm{p}} V_{\mathrm{ex}}}=\frac{z_{\mathrm{p}} C_{1}+z_{\mathrm{M}} C_{2}}{1-C_{1} V_{\mathrm{ex}}} \\
C_{\mathrm{M}}^{\mathrm{int}}=\frac{C_{\mathrm{M}}}{1-C_{\mathrm{p}} V_{\mathrm{ex}}}=\frac{C_{2}}{1-C_{1} V_{\mathrm{ex}}}
\end{gathered}
$$

and $y_{2}^{\text {int }}$ is the corresponding mean activity coefficient. As in Donnan equilibrium, we assume $y_{2}^{\text {int }}$ to be equal to that of a binary salt solution in equilibrium through a membrane with the ternary mixture. In this case, $y_{2}^{\text {int }}$ will depend only on $\mu_{2}$. By inserting eq $14 a, b$ into eq 13 , we obtain in the limit of $\mathrm{C}_{1} \rightarrow 0$ :

$$
\frac{\mu_{21}}{\mu_{22}}=-\left(\frac{\partial C_{2}}{\partial C_{1}}\right)_{\mu_{2}}=\frac{z_{\mathrm{p}}}{1+z_{\mathrm{M}}}+C_{2} V_{\mathrm{ex}}
$$

Accordingly, the change of $\mu_{21} / \mu_{22}$ and $\left(D_{21}\right)_{0} /\left(D_{22}\right)_{0}$ is linear with the salt concentration as it has been experimentally found. The intercept is due to the polyelectrolyte nature of the protein and represents the common-ion effect. According to this model, the slope quantifies the excluded volume of the protein. The calculated values of $V_{\text {ex }}$ are $\sim 20 \%$ larger than the lysozyme partial molar volumes for both $\mathrm{NaCl}$ and $\mathrm{MgCl}_{2}$. These are comparable to the lysozyme hydrodynamic volume. ${ }^{42}$

We will now compare this excluded volume model with a rigorous thermodynamic treatment of the protein-salt interactions.

Protein-Salt Thermodynamic Interactions. Protein-salt thermodynamic interactions are conveniently described by the chemical potential derivatives based on molality, as discussed by Arakawa et al.: ${ }^{1,25} \mu_{12}^{(m)} \equiv\left(\partial \mu_{1} / \partial \mu_{2}\right)_{T, p, m_{1}} \equiv\left(\partial \mu_{2} / \partial \mu_{1}\right)_{T, p, m_{2}}$ and $\mu_{22}^{(m)} \equiv\left(\partial \mu_{2} / \partial m_{2}\right)_{T, p, m_{1}}$. These quantities are related to the molarity-based derivatives by

$\mu_{12}^{(m)}=\left(d-C_{1} M_{1}-C_{2} M_{2}\right)\left[\mu_{21}\left(1-C_{1} \bar{V}_{1}\right)-\mu_{22} C_{2} \bar{V}_{1}\right]$

$\mu_{22}^{(m)}=\left(d-C_{1} M_{1}-C_{2} M_{2}\right)\left[\mu_{22}\left(1-C_{2} \bar{V}_{2}\right)-\mu_{21} C_{1} \bar{V}_{2}\right]$

where $d$ is the solution density in $\mathrm{g} \mathrm{dm}^{-3}$. The values of $\mu_{12}^{(m)}$ and $\mu_{22}^{(m)}$ obtained using eq 16a,b are reported in Tables 3 and 4, respectively, for $\mathrm{NaCl}$ and $\mathrm{MgCl}_{2}$. We observe that the values of $\mu_{12}^{(m)}$ closely match the values of $\mu_{12}$. Another useful parameter reported in Tables 3 and 4 is the preferential interaction coefficient $\Gamma_{\mu_{2}}: 1,25$

$$
\Gamma_{\mu_{2}} \equiv\left(\frac{\partial m_{2}}{\partial m_{1}}\right)_{T, \mu_{2}}=-\frac{\mu_{12}^{(m)}}{\mu_{22}^{(m)}}
$$

We now want to consider the relation of the preferential interaction parameters to the excluded volume parameter, $V_{\mathrm{ex}}$. Considering eq 17 and taking the ratio between parts $\mathrm{a}$ and $\mathrm{b}$ of eq 16 in the limit that $C_{1} \rightarrow 0$, we obtain:

$$
\frac{\mu_{21}}{\mu_{22}}=\Gamma_{\mu_{2}}\left(1-C_{2} \bar{V}_{2}\right)+C_{2} \bar{V}_{1}
$$

Because $\left(1-C_{2} \bar{V}_{2}\right) \approx 1.0$ for all our measurements (the actual value ranges from 0.96 to 1.00 ), we neglect this factor

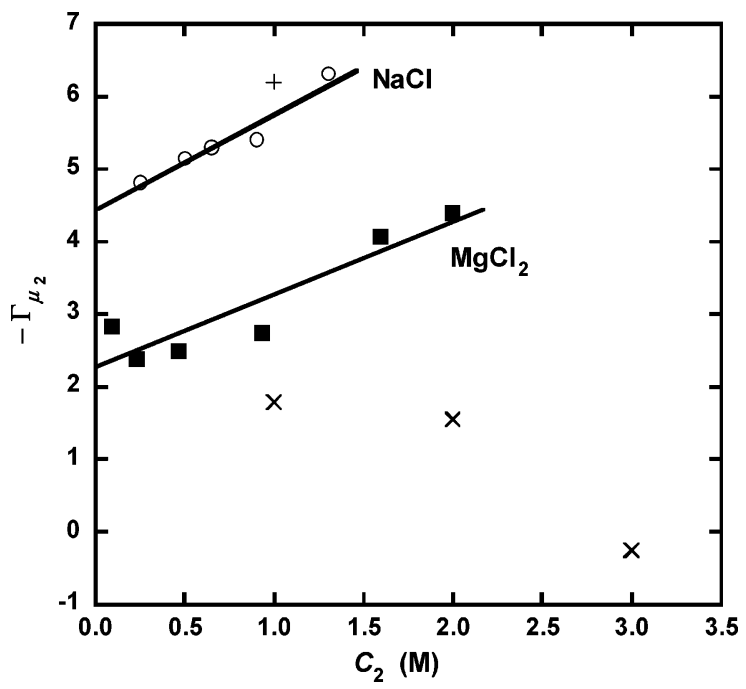

Figure 6. Preferential interaction coefficients reported as $-\Gamma_{\mu_{2}}$ as a function of salt concentration, $C_{2}$, for the lysozyme $-\mathrm{NaCl}-\mathrm{H}_{2} \mathrm{O}(\mathrm{O})$ and the lysozyme $-\mathrm{MgCl}_{2}-\mathrm{H}_{2} \mathrm{O}(\mathbf{\square})$ systems. Values at $20{ }^{\circ} \mathrm{C}$ taken from ref $39(\mathrm{NaCl},+)$, and ref $1\left(\mathrm{MgCl}_{2}, \times\right)$.

and rewrite eq 18 in the following way:

$$
-\Gamma_{\mu_{2}} \approx \frac{z_{\mathrm{p}}}{1+z_{\mathrm{M}}}+C_{2}\left(V_{\mathrm{ex}}-V_{1}\right)
$$

According to eq 19 , the preferential interaction parameter is linear in $C_{2}$. The intercept represents the common-ion effect as in the case of $\mu_{21} / \mu_{22}$. However, the slope is now the difference between the excluded volume and the partial molar volume of the protein. If $\bar{V}_{1}$ can be assumed to be the volume occupied by the macromolecules, $V_{\mathrm{ex}}-\bar{V}_{1}>0$ describes the excess of water surrounding the proteins (preferential hydration), while $V_{\text {ex }}-$ $\bar{V}_{1}<0$ describes the excess of salt surrounding the proteins (salt association). ${ }^{1}$

Our results on $-\Gamma_{\mu_{2}}$ are shown in Figure 6. The values of $-\Gamma_{\mu_{2}}$ for $\mathrm{NaCl}$ are higher than those for $\mathrm{MgCl}_{2}$. By fitting our data with straight lines, we find that the ratio of the two intercepts is $2.0 \pm 0.6$, consistent with the predicted value of $\approx 3 / 2$. We also find that the two slope values, which are $1.3 \pm$ $0.4 \mathrm{M}^{-1}$ for the $\mathrm{NaCl}$ case and $1.0 \pm 0.4 \mathrm{M}^{-1}$ for the $\mathrm{MgCl}_{2}$, are positive and approximately equal, as we expected from the parallelism of the two $\left(D_{21}\right)_{0} /\left(D_{22}\right)_{0}$ plots. This indicates the presence of protein preferential hydration in both cases with a preferential interaction contribution being roughly equal for both systems.

In Figure 6, we include literature values of $-\Gamma_{\mu_{2}}$ for aqueous lysozyme in $\mathrm{NaCl}^{42}$ (at $C_{2}=1 \mathrm{M}$ ) and in $\mathrm{MgCl}_{2}{ }^{1}$ (at $C_{2}=1$, $2,3 \mathrm{M})$ in the presence of acetate buffer ( $\mathrm{HAc} / \mathrm{NaAc}, 0.05 \mathrm{M}$, $\mathrm{pH} 4.5$ ) obtained by equilibrium-dialysis at $20^{\circ} \mathrm{C}$. In the case of $\mathrm{NaCl}$, our $\mu_{12}^{(m)}$ and $\Gamma_{\mu_{2}}$ are in good agreement with the literature value. In the case of $\mathrm{MgCl}_{2}$, the agreement at $C_{2}>1$ $\mathrm{M}$ is not good. Contrary to our results, the slope $V_{\mathrm{ex}}-\bar{V}_{1}$ is negative, suggesting significant $\mathrm{Mg}^{2+}$ binding, especially at high salt concentration. Possible sources of discrepancy are the presence of acetate-buffer components in the equilibriumdialysis experiments and the difference in temperature. However, we are unable to explain the observed differences.

We remark that our results show that the common-ion effect is an important contribution to the protein-salt thermodynamic interaction. It also appears to be the main source of difference between $\mathrm{NaCl}$ and $\mathrm{MgCl}_{2}$. 
We now consider the behavior of $\mu_{12}^{(m)} \approx \mu_{12}$ as a function of salt type and concentration. This quantity is important because it gives the increase of protein chemical potential as a function of salt concentration. In the case of $\mathrm{MgCl}_{2}, \mu_{12}^{(m)} \approx \mu_{12}$ and $\mu_{21}$ increase with $C_{2}$ at high salt concentration (see Figure 2a,b). This behavior was not observed for $\mathrm{NaCl}$ and represents an important difference between the two systems. We note that $\mu_{12}^{(m)}=-\Gamma_{\mu_{2}} \mu_{22}^{(m)}$. Thus, we can relate the observed differences in $\mu_{12}^{(m)}$ to the thermodynamic properties of the saltwater binary systems, ${ }^{32,33}$ represented by $\mu_{22}^{(m)} \approx\left(z_{\mathrm{M}}+1\right)\left(1+\partial \ln y_{2} / \partial \ln \right.$ $\left.m_{2}\right) / m_{2}$. In agreement with our results, the activity-coefficient term for $\mathrm{MgCl}_{2}$ significantly increases with $C_{2}$, but remains relatively small for $\mathrm{NaCl}$.

\section{Summary and Conclusions}

In this paper, we have reported the four diffusion coefficients for the lysozyme- $\mathrm{MgCl}_{2}$-water ternary system. The comparison with previous results on the lysozyme- $\mathrm{NaCl}$-water ternary system has allowed us to examine the effect of salt stoichiometry on the transport properties of protein-salt aqueous mixtures. We have found that the cross-diffusion coefficients, $D_{12}$ and $D_{21}$, are very sensitive to salt stoichiometry. We were able to predict most of the observed differences between the $\mathrm{MgCl}_{2}$ and $\mathrm{NaCl}$ cases by taking into account the charges of the metal ions and other properties of binary saltwater mixtures. The salt main-diffusion coefficient, $D_{22}$, can be directly related to the corresponding binary salt diffusion coefficient. The protein main-diffusion coefficient, $D_{11}$, is mainly affected by solution viscosity within our experimental domain. However, by reporting $\left(D_{11}\right)_{0}\left(\eta / \eta_{0}\right)$ as a function of $C_{2}$, we have found the presence of a minimum in the $\mathrm{MgCl}_{2}$ case. This behavior was not observed in the $\mathrm{NaCl}$ case. Our results suggest an increase in the thermodynamic factor, $\mu_{11}$, consistent with the presence of protein-protein repulsive interactions at high $\mathrm{MgCl}_{2}$ concentrations, in agreement with literature.

We have used all four ternary diffusion coefficients to extract chemical-potential cross-derivatives $\left(\mu_{11}\right.$ and $\left.\mu_{21}\right)$ and preferential interactions coefficients $\left(\Gamma_{\mu_{2}}\right)$. These thermodynamic data characterize the protein-salt thermodynamic interactions. We have argued that the quotient $\left(D_{21}\right)_{0} /\left(D_{22}\right)_{0} \approx \mu_{21} / \mu_{22}$ is essentially a thermodynamic property for both salt cases. This quotient, which linearly increases with salt concentration, can be separated into two parts. The first part, which is independent of salt concentration, can be related to the common-ion effect (or Donnan effect). We have corroborated the presence of common-ion effects by showing that this contribution for the $\mathrm{NaCl}$ case is higher than that for the $\mathrm{MgCl}_{2}$ case, consistent with salt stoichiometry. The same result is obtained from our $\Gamma_{\mu_{2}}$ values. The second part of this quotient, which can be described by an excluded volume model, is directly proportional to salt concentration. The corresponding slope is the volume of the protein molecules including their hydrated shells. We have found that the slope value for the $\mathrm{MgCl}_{2}$ case is about the same as that for the $\mathrm{NaCl}$ case, indicating the presence of similar protein preferential hydration for both salt cases. This is confirmed by our $\Gamma_{\mu_{2}}$ values. We conclude that both commonion effects and protein preferential hydration are important for describing protein - salt thermodynamic interactions. Our results also indicate that both $\mu_{11}$ and $\mu_{12}$ are crucial parameters for understanding the complex effect of salt on the protein thermodynamic behavior in solution.

Acknowledgment. We thank D. G. Miller and A. J. Pearlstein for insightful discussions. The support of the NASA
Microgravity Biotechnology Program through grant NAG8-1356 is gratefully acknowledged.

Supporting Information Available: Experimental ternary diffusion results. This material is available free of charge via the Internet at http://pubs.acs.org.

\section{References and Notes} 1914.

(1) Arakawa, T.; Bhat, R.; Timasheff, S. N. Biochemistry 1990, 29,

(2) Timasheff, S. N.; Xie, G. Biophys. Chem. 2003, 105, 421.

(3) Courtneay, E. S.; Capp, M. W.; Anderson, C. F.; Record, M. T., Jr. Biochemistry 2000, 39, 4455 .

(4) Ducruix, A.; Guilloteau, J.; Riès-Kautt, M.; Tardieu, A. J. Cryst. Growth 1996, 168, 28.

(5) Curtis, R.; Prausnitz, J. M.; Blanch, H. W. Biotechnol. Bioeng. 1998, 57,11

(6) Minton, A. P. Curr. Opin. Struct. Biol. 2000, 10, 34

(7) Annunziata, O.; Asherie, N.; Lomakin, A.; Pande, J.; Ogun O.; Benedek, G. B. Proc. Natl. Acad. Sci. U.S.A. 2002, 99, 14165.

(8) Retailleau, P.; Ducruix, A.; Riès-Kautt, M. Acta Crystallogr., Sect. D 2002, 58, 1576 .

(9) Annunziata, O.; Paduano, L.; Pearlstein, A. J.; Miller, D. G.; Albright, J. G. J. Phys. Chem. B 2006, 110, 1405.

(10) McPherson, A. Crystallization of Biological Macromolecules; Cold Spring Harbor Laboratory Press: Plainview, N, 1998.

(11) Rosenberger, F.; Vekilov, P. G.; Muschol, M.; Thomas, B. R. J. Cryst. Growth 1996, 167, 1.

(12) Tardieu, A.; Bonnete, F.; Finet, S.; Vivares, D Acta Crystallogr., Sect. D 2002, 58, 1549 .

(13) Liu, W.; Cellmer, T.; Keerl, D.; Prausnitz, J. M.; Blanch, H. W. Biotechnol. Bioeng. 2005, 90, 482.

(14) Ru, M. T.; Hirokane, S. Y.; Lo, A. S.; Dordick, J. S.; Reimer, J. A.; Clark, D. S. J. Am. Chem. Soc. 2000, 122, 1565.

(15) Wyman, J., Jr. Adv. Protein Chem. 1964, 19, 223.

(16) Clark, E. D. Curr. Opin. Biotechnol. 2001, 12, 202.

(17) George, A.; Wilson, W. W. Acta Crystallogr., Sect. D 1994, 50, 361.

(18) Finet, S.; Skouri-Panet, F.; Casselyn, M.; Bonnete, F.; Tardieu, A. Curr. Opin. Colloid Interface Sci. 2004, 9, 112.

(19) Annunziata, O.; Paduano, L.; Pearlstein, A. J.; Miller, D. G.; Albright, J. G. J. Am. Chem. Soc. 2000, 122, 5916.

(20) Leaist, D. G. J. Phys. Chem. 1989, 93, 474.

(21) Albright, J. G.; Annunziata, O.; Miller, D. G.; Paduano, L.; Pearlstein A. J. J. Am. Chem. Soc. 1999, 121, 3256.

(22) Paduano, L.; Annunziata, O.; Pearlstein, A. J.; Miller, D. G.; Albright, J. G. J. Cryst. Growth 2001, 232, 273.

(23) Tanford, C. Physical Chemistry of Macromolecules; Wiley: New York, 1961

(24) Warren, P. B. J. Phys.: Condens. Matter 2002, 14, 7617.

(25) We use the subscript "1" for the protein component and the subscript "2" for the salt component, consistent with the literature on multicomponent diffusion. However, the subscript "2" for the protein component and the subscript " 3 " for the salt component are extensively used in relation to the thermodynamic description of protein mixtures.

(26) Gosting, L. J. Adv. Protein Chem. 1956, 11, 429.

(27) Kirkwood, J. G.; Baldwin, R. L.; Dunlop, P. J.; Gosting, L. J.; Kegeles, G. J. Chem. Phys. 1960, 33, 1505.

(28) Dunlop, P. J.; Gosting, L. J. J. Phys. Chem. 1959, 63, 86.

(29) Woolf, L. A.; Miller, D. G.; Gosting, L. J. J. Am. Chem. Soc. 1962, 84,317 .

(30) Miller, D. G. J. Phys. Chem. 1986, 90, 1509

(31) Miller, D. G. J. Phys. Chem. 1959, 63, 570.

(32) Miller, D. G.; Rard, A. J.; Eppstein, L. B.; Albright, J. G. J. Phys. Chem. 1984, 88, 5739.

(33) Rard, J. A.; Miller, D. G. J. Sol. Chem. 1979, 8, 701

(34) Tanford, C.; Wagner, M. L. J. Am. Chem. Soc. 1954, 76, 3331.

(35) Annunziata, O.; Buzatu, D.; Albright, J. G. Langmuir 2005, 21, 12085

(36) Robinson, R. A.; Stokes, R. H. Electrolyte Solutions; Academic Press: New York, 1955.

(37) Isono, T. J. Chem. Eng. Data 1984, 29, 45.

(38) Zhang, H.-L.; Han, S.-J. J. Chem. Eng. Data 1996, 41, 516.

(39) Grisby, J. J.; Blanch, H. W.; Prausnitz, J. M. J. Phys. Chem. B 2000, 104, 3645 .

(40) Miller, D. G. J. Phys. Chem. 1967, 71, 616.

(41) Vergara, A.; Paduano, L.; Vitagliano V.; Sartorio R. Mater. Chem. Phys. 2000, 66, 126.

(42) Arakawa, T.; Timasheff, S. N. Biochemistry 1984, 23, 5912. 